\title{
Administrative Delays as Barriers to Trade
}

June 2003

Pierre Régibeau* and Katharine Rockett**

\begin{abstract}
One domestic firm and one foreign firm must decide when to introduce their new product to the home market. The home government may apply an import tariff, an administrative delay, or both to the product of the foreign firm. We show that the, while both the tariff and administrative delay can ensure the socially optimal timing of entry, the administrative delay is the less efficient instrument for maximising home welfare. If trade liberalization constrains the import tariff to be below its domestically optimal level, we show that the optimal administrative delay leads to lower levels of world welfare than the optimal tariff, so that trade liberalization can be welfare decreasing.
\end{abstract}

* Corresponding author: Department of Economics, University of Essex, Wivenhoe Park, Colchester, CO4 3SQ, UK. Email: pregib@essex.ac.uk

** University of Essex

The authors would like to acknowledge the generous support of ESRC grant L145251003 for this project.

We would like to thank participants to the Erwit conference (Copenhagen 2000) as well as seminar audiences at Birbeck College, Queens Mary \& Westfield, Royal Holloway, the University of East Anglia, the University of Exeter and the University of Kent for many helpful comments. 


\section{Introduction}

International trade in goods and services is restricted by a variety of governmental policies. Most prominent among these are trade policies that are explicitly designed to discriminate against products that are produced abroad. Trade policies take many forms from explicit tariffs or quotas to voluntary export restraints or the enforcement of anti-dumping laws. International trade flows are also impeded by policies that apply to both foreign and domestic firms, such as tax policies, intellectual property laws, safety standards or technical standards. These "internal" policies can affect trade in basically two ways. Firstly, the policies can be applied in a discriminatory manner: the relevant authorities can systematically take more time or be less accommodating when dealing with foreign products or foreign firms. Secondly, domestic firms might simply be more familiar with the local procedures so that local regulation is less of a burden for them than for their foreign competitors. In this case a country can discriminate against foreign firms by adopting idiosyncratic rules and ignoring attempts to standardize administrative procedures across countries.

There is some evidence of systematic pro-domestic bias in the application of domestic policies. For example, the fact that most companies obtain significantly more patents at home that in other important markets suggests that they perceive the costs of filing and litigating abroad as higher than at 
home. ${ }^{1}$ There also appear to be some systematic differences in the speed of administrative review of new products. The work of Dranove and Meltzer (1994) suggests that administrative delays may be greater for foreign-owned drug firms, and that the additional administrative delay suffered by foreign firms differs across countries. For example, they find that French-made drugs have a "dramatic" advantage of approval within France, while German-made drugs have a large advantage in Germany. US made drugs are found to be approved two to three years earlier in the United States than in France, the United Kingdom or Germany. Such bias can be privately and socially costly. For example, Gieringer (1985) estimates that a one year delay in the introduction of new drugs results in between 32,000 and 76,000 additional deaths per decade.

This paper analyzes the special case of administrative delays in the approval of new product designs as a barrier to trade. Because we are interested in the issue of delays, we choose a model with a significant timing dimension: we study a two-country framework where two firms, one domestic and the other foreign, must decide when to introduce their new product into the market. By waiting longer a firm increases the quality of its product but forgoes a current stream of profits. In the sub-game perfect equilibrium, the

\footnotetext{
${ }^{1}$ Another possible explanation for the discrepancy is that foreign companies feel that their products will not sell as well abroad because of the consumers' preference for domestic products. Expecting fewer sales, foreign companies would be less likely to invest in obtaining the patent even if the cost of patenting were the same at home and abroad. Still, this does not explain why international firms based in small countries would still have a greater propensity to patent at home than in much larger markets like the US.
} 
timing of introduction and the quality of both the domestic and the foreign goods are determined endogenously. The home government may apply an import tariff, an administrative delay or both to the product of the foreign firm. An administrative delay imposes a waiting period between the time when the quality of the foreign product is determined and the time when the product can actually be sold. Our main interest is the differential effect of the tariff and the administrative delay on the timing of new product introductions and the resulting change in home, foreign and world welfare. We attempt to answer three questions. First, can delays be an effective form of trade policy and, if the answer is "yes", what would an optimal delay policy look like? Second, how do administrative delays compare to traditional trade instruments such as a unit import tariff? Are these instruments equally efficient from the point of view of the home country? Do they affect world welfare in a similar manner? Finally, how would the home government and the firms react to a trade liberalization that imposes limits on the level of import tariffs? How would such trade liberalization affect the endogenous quality of the products? Would it necessarily improve world welfare?

The last question is of particular importance. As multilateral trade agreements progressively limit the use of the more traditional trade policy tools, policy makers are likely to make greater use of instruments that remain unregulated or that are harder to monitor for evidence of discrimination. In fact, the virtual elimination of formal import quotas and the strict limits 
imposed on most import tariffs seems to be one of the reasons behind the proliferation of voluntary export restraint agreements and the flourishing of anti-dumping actions. The potential for substitution has long been recognized by the Gatt/WTO as the later rounds of discussion have tried-without much success- to address the issue of internal barriers to international trade.

Our results suggest that administrative delays are a less efficient instruments for maximizing home welfare than tariffs. With a tariff, the home government can affect the timing of entry to ensure that the domestic firm moves first at the socially optimal date. Although an optimally chosen delay can achieve the same pattern of introduction, it does not yield any tariff revenues. As a result, if the tariff may be set optimally, administrative delays are not used in a discriminatory manner. Delays also lead to lower world-wide welfare than tariffs. This is because delays impose a period of unproductive waiting, while a tariff lets the foreign firm improve the quality of its product right up to the date of introduction. If trade liberalization constrains the import tariff to be below its domestically optimal level, discriminatory administrative delays may become part of the optimal policy of the home country. As the optimal delay policy leads to lower levels of world welfare than the optimal tariff, trade liberalization can be welfare decreasing.

To our knowledge, the formal analysis of administrative delays is new to 
the literature on international trade. ${ }^{2}$ On the other hand, the effect of tariff protection on the optimal timing of technology adoption has been studied in two recent papers. ${ }^{3}$ Myagiwa and Ohno (1995) discuss how import restrictions can affect a home firm's incentives to "close the technology gap" with respect to a foreign competitor. They use a technology adoption model that is similar to ours ${ }^{4}$ but assume that the foreign firm has adopted the new technology already. They then focus on how tariffs and quotas would affect the date at which the domestic competitor would also adopt. Hence, they do not study the instrument that is the focus of our work, the administrative delay. Further, they cannot examine, as we do, how trade policies influence the order of technological adoption between foreign and domestic firms. Chuman and Kusumoto (1995) extend the analysis of Myagiwa and Ohno to compare price and quantity setting competition under various specifications of demands. They show that the effect of tariff protection on the adoption behavior of the domestic firm does, indeed, depend on the nature of competition as well as on the precise shapes of demand and cost functions. We eschew such complications by assuming that consumer demand is perfectly inelastic at any point in time. This simplification has numerous advantages. First, as mentioned above, it makes it possible to study the timing decisions

${ }^{2}$ Noll (1985) provides a synthesis of the work of many authors from other social sciences who have studied administrative delays.

${ }^{3}$ Also see Brander and Spencer (1983) for an analysis of the relationship between trade policies and innovation.

${ }^{4}$ They assume that the cost of adopting the new technology decreases over time while we assume that the quality of the product increases over time. The basic logic of these two classes of models is very similar. 
of both the foreign and the domestic firms. Indeed, the interaction between the firms' adoption strategies is central to our analysis. Second, with inelastic demands the profit-maximizing behavior of a single firm would be socially optimal. This ensures that all distortions arising in our model are rooted in the rivalry between the domestic and foreign producers. To investigate the significance of this assumption, we highlight the results that are robust to relaxing this assumption in a latter part of the paper. Summarizing, our model contributes a first formal analysis of administrative delays as trade barriers and illustrates in detail a mechanism by which these delays could affect world and country welfare in a model of endogenous timing of technological adoption. A further contribution of the paper is to study both the case of drastic and partial trade liberalization on the use of tariffs and administrative delays. As far as we know, this is novel to the literature evaluating the substitution from traditional to non-traditional trade barriers, and allows us to study the case where both instruments could be used concurrently.

The organization of the paper is as follows. Section 1 presents our benchmark free-trade model. Section 2 analyses the case where the home country has only the tariff at its disposal while Section 3 considers the exclusive use of administrative delays. Section 4 compares the optimal policies of Sections 2 and 3 and examines the effect of trade liberalization, allowing the home government to use both instruments simultaneously. Section 5 discusses the 
robustness of our results to changes in the timing of the policy decisions and in the type of demand functions. Section 6 concludes. Most proofs have been relegated to the Appendix.

\section{The Model and Benchmark Case}

Two firms, A and B, must determine when to introduce their product in the market. Before time zero, neither firm is ready to sell a product that would be acceptable to consumers. From time zero on, each firm can introduce a product that incorporates the "state of the art" technology at the time of introduction. The rate of technological progress is exogenous to the firms. The longer the firm waits, the higher the quality of the good it can sell. More specifically, the quality of the good which is introduced at time $t_{i}$ is $q_{i}=\theta t_{i}$. Once a firm has introduced its product, its quality is fixed forever. This captures the idea that a firm cannot keep incorporating new technology into its product as fast once the product has been introduced and the basic design choices have been made. ${ }^{5}$ Finally, each firm can make only a single product introduction. The analysis would be essentially unchanged if firms were allowed to continuously incorporate improvements after the date of initial introduction as long as the rate of quality improvement drops from $\theta$ to $\theta_{L}<$ $\theta^{6}$. One could also accommodate a larger number of discrete introductions

${ }^{5}$ While we believe that this assumption is reasonable, it clearly does not apply to every industry. In particular, in industries where innovation benefits significantly from the input of customers, the rate of product improvement might in fact be larger once the first generation of the product has been introduced.

${ }^{6}$ See Dutta and Rustichini (1993). 
as long as the total number of introductions available to each firm were exogenous. This would, however, significantly complicate the calculations and detract from the clarity of the presentation ${ }^{7}$ without altering the main results. Once a firm has introduced its version of the new good, it can produce at a constant marginal cost, c. For simplicity, we set c to zero. Firms compete in prices if both produce in the market.

At each time, indexed by $x$, a mass, $\mathrm{N}$, of new identical consumers arrives in the market. Each of these consumers buys at most one unit of the good. Either this purchase occurs immediately or the consumer disappears from the market forever ${ }^{8}$. A consumer who buys one unit of good $\mathrm{j}$ at time $x$ enjoys benefits of $\mathrm{V}_{j}=q_{j}$ where $\mathrm{q}_{j}$ is the quality of good $\mathrm{j}$. The products of the two firms are not horizontally differentiated so that all consumers always prefer the good that offers them the highest quality price difference, $q_{j}-p_{j}$.

We assume that all consumers are located in country A, to which we will refer as the home, or domestic, market. Firm A is located in country A as well, whereas firm B is located abroad and exports to market A. In our baseline case, country A has no policy instruments at its disposal to affect the firms' behavior.

${ }^{7}$ On the other hand, this type of timing model does not easily accommodate endogenously determined numbers of discrete introductions. In fact, we are not aware of any oligopoly model where both the number of introductions (or innovations) and their timing (or the intensity of R\&D) are endogenous.

${ }^{8}$ This assumption is made to rule out strategic waiting behavior on the part of consumers, as our focus is on strategic waiting by firms. 
We solve for the subgame perfect equilibrium of the continuous time game $^{9}$. The first point to understand is that the two firms will never decide to introduce their products simultaneously. Simultaneous introduction would drive down equilibrium prices to zero, as both firms would offer homogenous products of identical quality. In any equilibrium, then, there will be a leader, who introduces first, and a follower. Considering the problem of the second mover, the introduction decision is determined by maximizing the discounted stream of profits that accrues to the follower after entry. Since the follower introduces later, it offers the higher quality product. It can then charge a price equal to the difference between the value it offers, $\mathrm{V}_{f}$, and the value offered by the leader, $\mathrm{V}_{l}$, and still make all sales. If we define $\mathrm{t}_{f}$ as the delay between the introduction date of the leader and the follower, then the revenue earned by the follower per period is:

$$
P_{f} N=N\left[V_{f}-V_{l}\right]=N\left[q_{f}-q_{l}\right]=\theta t_{f} N
$$

and the stream of profits of the follower discounted back to the time of entry of the leader is:

$$
\pi_{f}=e^{-r t_{f}} \int_{0}^{\infty} \theta t_{f} N e^{-r x} d x=e^{-r t_{f}} \frac{\theta N t_{f}}{r}
$$

Maximizing this with respect to $t_{f}$, we obtain an optimal delay of $t_{f}^{*}=\frac{1}{r}$.

${ }^{9}$ This is a slight abuse of language since the concept of subgame perfection is not properly defined in continuous time. One should think of our results as applying to the limit of a discrete time game as the time grid of the game becomes arbitrarily fine. 
Similarly, the leader makes all sales from its date of entry until the follower's date of entry. During this time, the leader can extract the entire consumers' surplus $V_{l} N$ as revenue. This leads to the following expression for discounted profits of the leader:

$$
\pi_{L}=e^{-r t_{l}} \int_{0}^{t_{f}} \theta t_{l} N e^{-r x} d x=e^{-r t_{l}} \frac{\theta N t_{l}}{r}\left(1-e^{-r t_{f}}\right)
$$

Maximizing this with respect to $t_{l}$, we obtain an optimal entry date of $t_{l}^{*}=\frac{1}{r}$. We will call this the "stand alone" or the "maturation" entry date for the leader. This is the date of introduction that would maximize firm A's profits under the assumption that firm B will introduce its product later, after its profit-maximizing delay. It will become important later in the paper to note that the leader's optimal introduction date is independent of the follower's entry date. In other words, the leader's entry date is determined by the trade-off between time of entry and the level of profit (quality of output) attainable per period. The follower's entry date affects the level of profit earned, but not this basic trade-off and so does not affect the choice of entry date by the leader. 


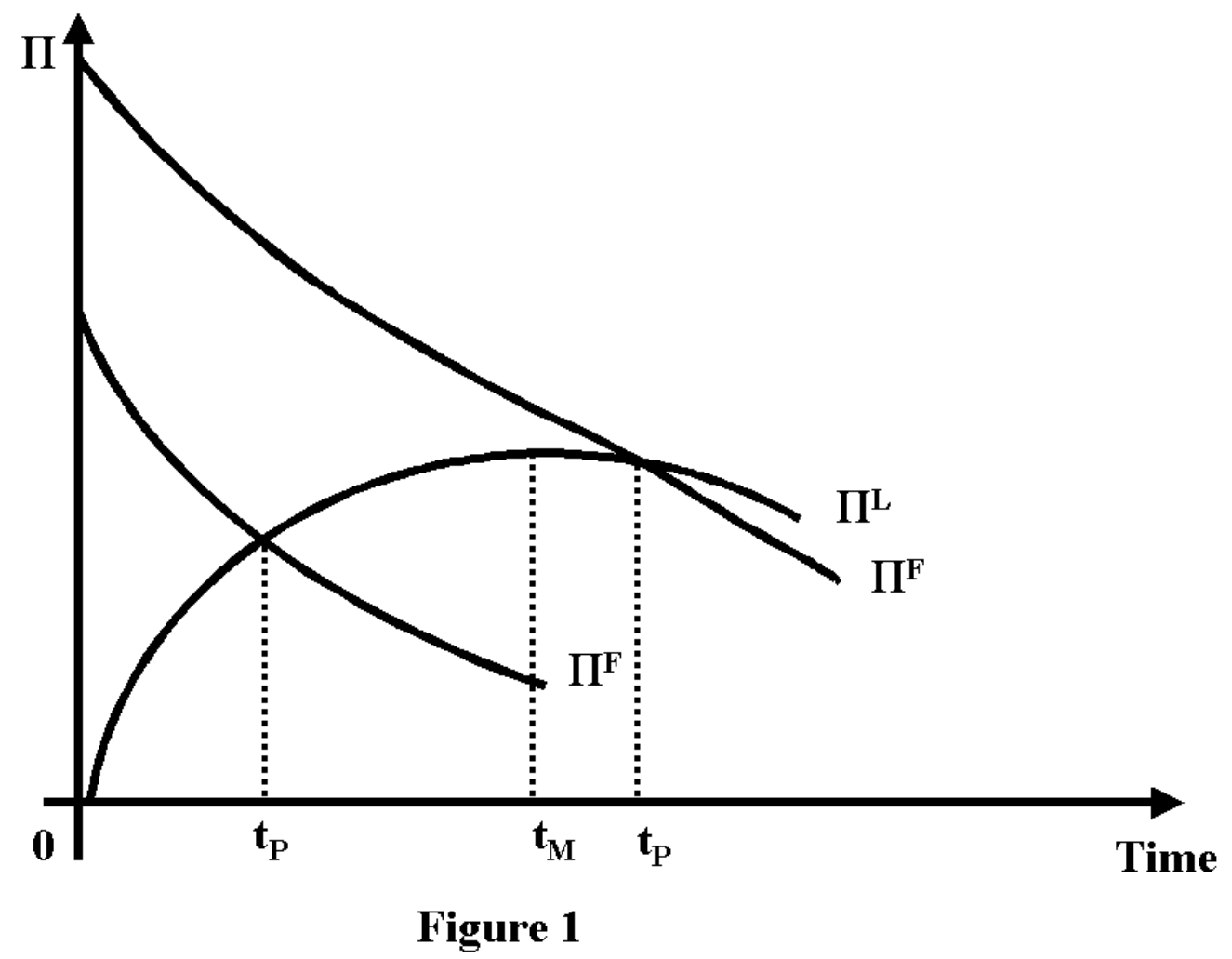

Having described the profit-maximizing introduction dates of both leader and follower, we can now characterize the (unique) subgame perfect equilibrium outcome of the game. ${ }^{10}$ This is illustrated in figure 1 , where the horizontal axis measures the date of introduction of the leader. The discounted value of the follower's profits, $\Pi^{F}$, decreases as the leader waits longer to introduce. On the other hand, given the anticipated optimal reaction of the follower, the discounted value of the leader's profits, $\Pi^{L}$, attains its maximum at $t_{M}=1 / r . \Pi^{F}$ intersects $\Pi^{L}$ at time $t_{p}$. One of two situations might arise.

\footnotetext{
${ }^{10} \mathrm{We}$ will limit ourselves to pure strategy equilibria.
} 
If $t_{p}$ is larger than $t_{M}$ then both firms are happy to wait until $t_{M}$, where one of them introduces first. ${ }^{11}$ If $t_{p}$ is smaller than $t_{M}$ the profits of the follower at $t_{M}$ are lower than the profits of the leader. The follower would, therefore, prefer to preempt the other firm by moving a little bit before $t_{M}$. In this way, the first introduction at $t_{M}$ can no longer be an equilibrium. The incentive to preempt persists as long as leading is more profitable than following. The equilibrium outcome is, therefore, for one firm to introduce first at $t_{p}$, where the leader and the follower make the same profits. The "preemption" date, $\mathrm{t}_{p}$, is formally defined as the time of first introduction equalizing the profits of the first and second movers, i.e., $\mathrm{t}_{p}$ is such that:

$$
\pi_{L}\left(t_{f}, t_{p}\right)=\pi_{f}\left(t_{f}, t_{p}\right)
$$

or, substituting $\mathrm{t}_{f}$ from above and simplifying,

$$
t_{p}\left(1-e^{-1}\right)=\frac{e^{-1}}{r}
$$

This calculation yields a preemption time of $\mathrm{t}^{p}=\frac{1}{r} \frac{e^{-1}}{1-e^{-1}}<\frac{1}{r}=t_{M}$, ensuring a unique (up to a permutation of the two firms) subgame perfect equilibrium of the game where one firm introduces at $t_{p}$ and the other follows at $t_{p}+t_{f}^{*}=t_{p}+\frac{1}{r} \cdot{ }^{12}$.

\footnotetext{
${ }^{11}$ At $t_{M}$ the profits of the follower exceed those of the leader. This does not mean that the 'leader' has an incentive to wait further. In any pure strategy equilibrium, each firm knows whether it is destined to be leader or follower. Hence the leader maximizes its profits by stopping at $t_{M}$. See Dutta and Rustichini (1993).

${ }^{12}$ For a formal proof that this is the unique subgame perfect outcome, see Dutta and Rustichini (1993) or Prokop, Regibeau and Rockett (1993).
} 
The welfare of the home country, computed as the unweighted sum of consumer surplus and the profit of the home firm discounted at time 0 is:

$$
\begin{gathered}
W_{A}=\int_{t_{o}}^{t_{p}+t_{f}^{* *}} N \theta t_{p} e^{-r x} d x+\int_{t_{p}+t_{f}^{* *}}^{\infty} N \theta t_{p} e^{-r x} d x=\int_{t_{p}}^{\infty} N \theta t_{p} e^{-r x} d x= \\
e^{-\frac{e^{-1}}{1-e^{-1}} \frac{N \theta}{r^{2}}\left[\frac{e^{-1}}{1-e^{-1}}\right]}
\end{gathered}
$$

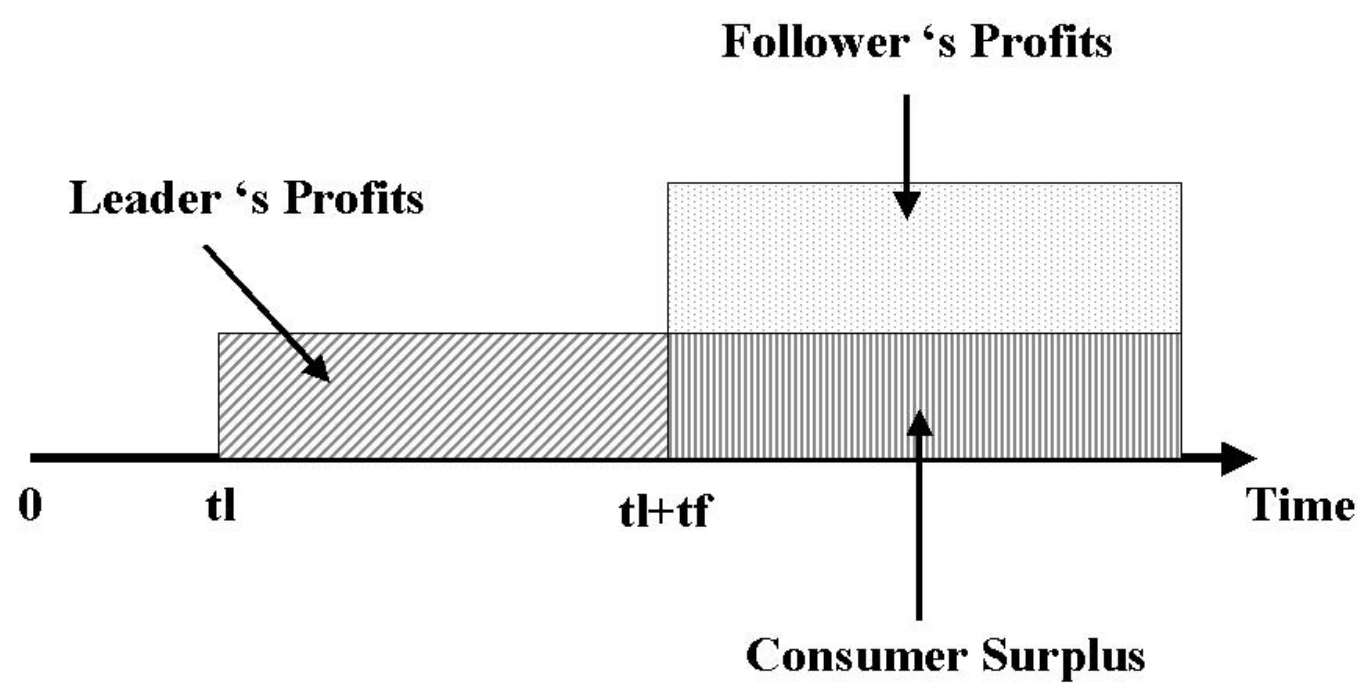

Figure 2

where we have assumed that the domestic firm has introduced first. Since the profits of the leader and follower are equalized, the welfare of country A 
would be the same if we had assumed that the foreign firm had introduced first. The components of this welfare function are shown in figure 2 . The domestic firm introduces at time $t_{l}$ and captures instantaneous profits equal to the quality of its product. This quality corresponds to the height of the first rectangle. At $t_{l}+t_{f}$ the foreign firm introduces a product of higher quality. The quality advantage of the foreign firm is the height of the upper rectangle. This quality differential is completely appropriated by the foreign firm leaving domestic consumers, and hence the home country, with an instantaneous surplus equal to the height of the lower rectangle. Since this height is equal to the quality of the domestic product, the instantaneous welfare of the home country is constant from the date of first introduction onwards. The welfare of the foreign country is equal to the discounted profits of the foreign firm, that is:

$$
W_{B}=\int_{t_{p}+t_{f}^{* *}}^{\infty} N \theta t_{f}^{*} e^{-r x} d x=\frac{N \theta}{r^{2}} e^{-1} e^{-\frac{e^{-1}}{1-e^{-1}}}
$$

To be able to evaluate the effectiveness of trade policies we must also understand the socially optimal pattern of introduction. Consider first the benchmark where both firms are domestic firms. This will give us the world welfare maximizing dates of introduction. We can write

$$
W=\int_{t_{l}}^{t_{l}+t_{f}} N \theta t_{l} e^{-r x} d x+\int_{t_{l}+t_{f}}^{\infty} N \theta\left(t_{l}+t_{f}\right) e^{-r x} d x
$$

Maximizing this expression with respect to $t_{l}$ and $t_{f}$ yields the socially optimal dates of introduction $t_{l}=\frac{1-e^{-1}}{r}$ and $t_{f}=\frac{1}{r}$ so that the second firm 
introduces at $\frac{1}{r}\left(2-e^{-1}\right)$. The delay between first and second introductions is the same as would be chosen by the firms. On the other hand, the socially optimal date of first introduction comes earlier than the privately optimal stand alone date of introduction: while the leader only cares about its own profits, the social planner considers the fact that a later date of first introduction also delays the introduction of the better quality secondgeneration product.

Now consider the situation where the social planner can still choose both $t_{l}$ and $t_{f}$ but $\mathrm{A}$ is a domestic firm and $\mathrm{B}$ is foreign. One can show ${ }^{13}$ that the welfare of the home country is maximized if the home firm introduces first at time $t_{l}=\frac{1}{r}$. The introduction date of the foreign follower is irrelevant. The intuition for this result is straightforward. Since the foreign firm captures all of the surplus that it creates, the social planner only cares about maximizing the discounted value of the value created by the domestic firm. As the domestic firm also captures the whole consumer surplus during its period of monopoly, the socially optimal date of introduction is equal to the privately optimal 'stand alone' date of introduction ${ }^{14}$. At the social optimum we have $W_{A}^{S}=\frac{\theta N}{r^{2}} e^{-1}$. Hence we see that, in the presence of a foreign firm, the socially optimal introduction date is later than the equilibrium preemption date $t_{p}$. Moreover, the social planner is not indifferent as to the order of

\footnotetext{
${ }^{13}$ See Appendix A, section 3.
}

${ }^{14}$ The domestic firm only captures the value $\theta t_{l}$ from $t_{l}$ to $t_{l}+t_{f}$ while country A as a whole enjoys this surplus from $t_{l}$ to infinity. This just means that the discounted profits of the domestic firms are only equal to a fixed proportion of the discounted welfare of the home country so that their maximand is the same. 
introduction: the country is better off if its home firm moves first. ${ }^{15}$ Policy makers will therefore be interested in any instrument that can delay the date of first introduction and ensure that the home firm moves first.

\section{Tariffs}

Assume that the home country may impose a permanent per unit tariff, $\mu$, on the imports of the foreign firm. As we have just seen, for a given date of introduction by the domestic firm, the introduction of a second-generation product by the foreign firm does not affect the welfare of the home country. The only consequence of the foreign firm's entry is that the instantaneous profit of the domestic firm now becomes the surplus captured by domestic consumers. Therefore, the home country would be better off if it could simply exclude the foreign firm from the market. This would ensure that the domestic firm introduces at its stand alone date $t_{l}^{*}=1 / r$, which is the same as the socially optimal date of introduction. Exclusion amounts to setting $\mu \rightarrow \infty$. Any other tariff would eventually be overcome, as the foreign firm would simply wait until the quality of its product has improved enough to outweigh its unit cost disadvantage.

The question is, then, whether the country can do better than this by capturing some of the additional surplus created by the foreign firm. The answer to this question is 'yes'. Indeed, by setting an appropriate tariff, the

${ }^{15}$ This is because, for all $t_{l}>t_{p}$, the discounted profits of the leader exceed those of the follower. See Figure 1. 
home country can ensure that its domestic firm moves first, that it does so at the socially optimal time $t_{l}=1 / r$, and that the discounted value of tariff revenues conditional on the foreign firm moving last are maximized.

We assume that the home country can commit to a tariff level $\mu$ at time zero. $^{16}$ This tariff can drastically affect the nature of the subgame perfect equilibrium. Let us first consider the optimal waiting time of the follower. If the domestic firm moves last, its optimal waiting time is still $t_{A}^{f}=\frac{1}{r}$. If the foreign firm moves last, however, its discounted profits are now:

$$
\pi_{B}^{f}=e^{-r t_{f}} \int_{0}^{\infty} N\left(\theta t_{f}-\mu\right) e^{-r x} d x=e^{-r t_{f}} \frac{N}{r}\left(\theta t_{f}-\mu\right)
$$

Maximizing this expression with respect to $t_{f}$ results in an optimal entry date of $t_{B}^{f}=\frac{1}{r}+\frac{\mu}{\theta}$. Hence, the tariff increases the delay in entry of the foreign firm when it is a follower. Intuitively, the tariff does not affect the marginal gain from waiting since the firm can still fully appropriate any increase in quality beyond the quality offered by the domestic incumbent. On the other hand, the tariff decreases the marginal cost of waiting since it reduces the level of instantaneous profits that must be forgone. ${ }^{17}$

\footnotetext{
${ }^{16}$ The consequemces of relaxing this assumption are discussed in Section 5.

${ }^{17}$ This suggests that an ad valorem tariff would leave the date of introduction of a foreign follower unchanged since it would affect the level of instantaneous profit and the marginal benefits from quality increase proportionally. However this neutrality stems from assuming zero marginal costs of production. If the marginal cost is positive, it is easy to show that an ad valorem tariff would also delay the introduction of the foreign product.
} 
Turning to the introduction time of the leader, we see that the stand alone entry date of the domestic firm is not affected by the tariff in spite of the fact that the domestic firm knows that the foreign follower will now introduce later. This is because, as mentioned earlier, the optimal delay of the follower only affects the discounted profits of the stand alone leader as a multiplicative factor, i.e. $\pi_{L}=\int_{t_{l}}^{t_{l}+t_{f}} N \theta t_{l} e^{-r x} d x=\frac{N \theta}{r} e^{-r t_{l}}\left(1-e^{-r t_{f}}\right)$. On the other hand, the stand alone entry date of a foreign leader is affected by the tariff in exactly the same manner as the foreign firm's optimal following delay was: the tariff decreases the marginal cost of waiting but leaves the marginal benefit unchanged. More formally, we have:

$$
\pi_{B}^{l}=e^{-r t_{l}} \int_{0}^{t_{A}^{f}} N\left(\theta t_{l}-\mu\right) e^{-r x} d x=N\left(\theta t_{l}-\mu\right) e^{-r t_{l}}\left(1-e^{-r t_{A}^{f}}\right)
$$

Notice that this expression has the same form as that of $\pi_{B}^{f}$, above, with the exception of the upper limit of integration. The profit-maximizing entry date, $\mathrm{t}_{B}^{\mu}=\frac{1}{r}+\frac{\mu}{\theta}$, is therefore the same as the foreign firm's optimal delay $t_{B}^{f}$. A positive tariff induces a 'stand alone' foreign leader to delay its date of entry.

We still need to determine the effect of the tariff on the preemption dates. In the symmetric case, $t_{p}$ was obtained by equating the discounted profits of a leader to the discounted profits of a follower. Because of the tariff, however, we must now distinguish between the preemption dates of the domestic and foreign firms. The preemption date of the domestic firm is the date that 
equalizes the discounted profits of that firm as a stand alone leader to its discounted profits as a follower, i.e., $t_{l}$ such that:

$$
\int_{t_{l}}^{t_{l}+t_{B}^{f}} N \theta t_{l} e^{-r x} d x=\int_{t_{l}+t_{A}^{f}}^{\infty} N \theta t_{A}^{f} e^{-r x} d x
$$

which yields $t_{A}^{P}=\frac{1}{r} \frac{e^{-1}}{1-e^{-1} e^{-r \frac{\mu}{\theta}}}$. Notice that this date is decreasing in $\mu$ : in the presence of a positive tariff the domestic firm is willing to move earlier in order be first - than it was under free trade. The intuition for this result is simple. Conditional on a first entry date $t_{l}$, the profits of the domestic firm as a follower are not affected by the tariff: it still introduces at $t_{l}+\frac{1}{r}$ and makes instantaneous profits of $\frac{N \theta}{r}$. On the other hand, for any given $t_{l}$, the domestic firm's profits as a leader increase because the foreign follower now introduces its product later. That is, the domestic leader now enjoys a longer period of monopoly. Hence, at the initial tariff-free preemption date $t_{p}$, the domestic leader's profits with the tariff exceed the domestic follower's profits with the tariff. This makes the domestic firm willing to move even earlier in order to be first.

Similarly, the preemption date of the foreign firm is the date $t_{l}$ that equalizes the foreign firm's profits as a leader to its profits as a follower, that is:

$$
\int_{t_{l}}^{t_{l}+t_{A}^{f}} N\left[\theta t_{l}-\mu\right] e^{-r x} d x=\int_{t_{l}+t_{B}^{f}}^{\infty} N\left[\theta t_{B}^{f}-\mu\right] e^{-r x} d x
$$


which yields $t_{B}^{P}=\frac{1}{r} \frac{e^{-1}}{1-e^{-1}} e^{-\frac{r \mu}{\theta}}+\frac{\mu}{\theta}$. This date is increasing in $\mu$ : in the presence of a tariff, the foreign firm is less willing to move early in order to be first than under free trade. The intuition is that, in the thought experiment that defines its preemption date, the foreign firm has an extra degree of freedom to react to the tariff when it is a follower. For a given date of introduction, $t_{p}$, by the domestic leader, the foreign firm can adjust its own date of introduction to lessen the adverse effect of the tariff. On the other hand, the profits of the foreign firm as a leader are computed for the same given date of first introduction so that no such adjustment is possible. Hence the foreign firm's profits as a leader are hurt more by the tariff than the foreign firm's profits as a follower.

In the free trade equilibrium, we had $t_{p}<t_{l}^{*}=1 / r$. The introduction of a tariff leaves $t_{A}^{l}=1 / r$, increases $t_{B}^{l}$ to $\frac{1}{r}+\frac{\mu}{\theta}$, decreases $t_{A}^{P}$, and increases $t_{B}^{P}$. This leaves us with two possible situations, depending on the size of the tariff compared to some threshold level, $\mu^{\#}$.:

case 1: $\mu<\mu^{\#:} \quad \mathrm{t}_{A}^{P}<t_{B}^{P}<t_{A}^{l}<t_{B}^{l}$

case 2: $\mu>\mu^{\#}: \quad \mathrm{t}_{A}^{P}<t_{A}^{l}<t_{B}^{P}<t_{B}^{l}$

In the first of these two cases, the unique subgame perfect equilibrium in 
pure strategies has firm A introduce first at $t_{B}^{P} \cdot{ }^{18}$ Intuitively, the domestic firm is willing to move as early as $t_{A}^{P}$ in order to be first. Still, it prefers to move (first) as closely as possible to its stand alone date $t_{A}^{l}$. Therefore, firm A waits up to the date, $t_{B}^{P}$, where firm $\mathrm{B}$ would be willing to preempt it. In the second case, firm A knows that firm B cannot credibly preempt before $t_{B}^{P}$. Since $t_{B}^{P}>t_{A}^{l}$, A can wait until its preferred date of introduction and move first at $t_{A}^{l}$. One can show that the welfare-maximizing tariff must be high enough to lead to this second type of equilibrium.

Proposition 1 The welfare maximizing tariff is $\mu^{*}=\frac{\theta}{r}$. At the optimal tariff, the domestic firm introduces first at time $t_{l}=\frac{1}{r}$ and the foreign firm introduces last at date $\frac{3}{r}$.

Proof. : See Appendix A, sections 1 and 2.

The level of home welfare under the optimal tariff policy is:

$$
W_{A}^{\mu}=\int_{1 / r}^{\infty} N \theta\left(\frac{1}{r}\right) e^{-r x} d x+\int_{3 / r}^{\infty} N \frac{\theta}{r} e^{-r x} d x=\frac{N \theta}{r^{2}} e^{-1}\left(1+e^{-2}\right)
$$

The optimal tariff increases the welfare of the home country in three ways. First, it allows the domestic firm to introduce first at its preferred stand alone date of $t_{l}=1 / r$, increasing its discounted profits. Second, the tariff raises the quality of the home product. This imposes a more severe competitive constraint on the foreign entrant, ensuring that domestic customers obtain

${ }^{18}$ For a formal characterization of these equilibria, see Prokop, Regibeau and Rockett (1993). 
a larger surplus after the introduction of the second-generation product by the foreign firm. Finally, the government collects positive discounted tariff revenues.

The foreign firm clearly suffers from the tariff due to the loss of tariff revenue and its later introduction date. The effect of the tariff on world welfare is not a priori obvious. Because we have inelastic demands, the tariff revenue is a pure transfer that leaves world welfare unchanged. The effect of the tariff on the dates of introduction actually lowers world welfare, for two reasons. First, as we saw in our benchmark model, the worldwide optimal delay between the two introductions is equal to the delay, $1 / r$, that firms would choose under free trade. The tariff increases this delay, resulting in a loss of welfare. Second, the tariff unduly postpones the introduction of the first generation product. Even though the date chosen under optimal tariff protection, $1 / r$, is optimal for the home country, it fails to take into account that later introduction also postpones the arrival of the superior second-generation product. In fact, as the worldwide optimal date of first introduction is almost identical to the equilibrium date of introduction under free trade ${ }^{19}$, the tariff-induced delay actually decreases world welfare.

Proposition 2 World welfare is lower under the optimal tariff than under free trade

\footnotetext{
${ }^{19}$ The worldwide optimal date is $\frac{1-e^{-1}}{r}$, which is higher than the preemption date $\frac{e^{-1}}{r\left(1-e^{-1}\right)}$.
} 
Proof. Under free trade, world welfare is equal to $W^{F}=\frac{e^{-1} N \theta}{r^{2}}\left[e^{-\frac{e^{-1}}{1-e^{-1}}}\right]\left[\frac{2-e^{-1}}{1-e^{-1}}\right]$.

At the optimal tariff we have $W^{\mu}=\int_{1 / r}^{\infty} N \theta\left(\frac{1}{r}\right) e^{-r x} d x+\int_{3 / r}^{\infty} N \theta\left(\frac{2}{r}\right) e^{-r x} d x=$ $\frac{e^{-1} N \theta}{r^{2}}\left[1+2 e^{-2}\right]<W^{F}$.

\section{Administrative Delay}

We analyze the case where country A may impose a delay, $\lambda$, on the foreign firm before it can actually sell its products in the home market. We assume that firm B cannot continue improving the quality of its product once the delay has begun, reflecting the idea that $\lambda$ represents an administrative delay required to gain approval for sale of a particular product as opposed to sale by a particular firm in market $\mathrm{A}$.

Let us now recalculate the equilibrium entry dates for the firms. If the foreign firm moves last, its discounted profits can be written as follows:

$$
\pi_{B}^{f}=e^{-r\left(t_{f}+\lambda\right)} \int_{0}^{\infty} N \theta t_{f} e^{-r x} d x=e^{-r\left(t_{f}+\lambda\right)} \frac{\theta N}{r} t_{f}
$$

where $t_{f}$ is the time that elapses between the introduction of the home product and the date at which the foreign firm begins the approval process. Accordingly, we will refer to $t_{f}$ as the 'application delay'. Note that, because the design of the product (and, hence, its quality) is fixed at the beginning of the administrative delay, the per period profit of the foreign firm does not include an allowance for an increment in quality while the approval process 
runs its course. Maximizing this expression with respect to $t_{f}$ yields a profitmaximizing delay of $t_{f B}^{\lambda}=\frac{1}{r}$. This means that the foreign product is actually for sale in the market $\frac{1}{r}+\lambda$ later than the home product. The entry delay that would be chosen by a domestic follower is the same as in the baseline case, i.e. $t_{f A}^{\lambda}=\frac{1}{r}$.

If the foreign firm is a leader, its discounted profits can be written as follows:

$$
\pi_{B}^{L}=\int_{t_{l}+\lambda}^{t_{f A}^{\lambda}+t_{L}} \theta N t_{L} e^{-r x} d x=\frac{\left(e^{-r \lambda}-e^{-r t_{f}}\right) \theta N}{r}\left[t_{L} e^{-r t_{l}}\right]
$$

provided that $\lambda \leq t_{f A}^{\lambda}=\frac{1}{r} .{ }^{20}$ Maximizing this expression with respect to $t_{l}$ yields an optimal application date of $\mathrm{t}_{l B}^{\lambda}=\frac{1}{r}$, corresponding to an optimal introduction date of $\frac{1}{r}+\lambda$. Note that the administrative delay does not affect the per period profit that can be earned by the leader since quality is fixed at the beginning of the delay. Rather, the delay merely shortens the period during which profits can be earned. This is the case as long as the administrative delay is short enough that there is no change in the order of entry that has been assumed (i.e., the foreign firm is the leader and the domestic firm is the follower). In other words, the administrative delay must not exceed $\frac{1}{r}$.

\footnotetext{
${ }^{20}$ If the administrative delay exceeds $\frac{1}{r}$, then a foreign leader always finds itself preempted by the domestic follower as the domestic firm optimally enters at $t_{l}+\frac{1}{r}$. Therefore, the foreign firm never moves first, letting the domestic firm introduce at $t_{l}=\frac{1}{r}$.
} 
If the leader is the domestic firm, its profits can be written as:

$$
\pi_{A}^{L}=e^{-r t_{l}} \int_{0}^{t_{f}+\lambda} \theta N t_{L} e^{-r x} d x=e^{-r t_{L}} \frac{\theta N t_{L}}{r}\left(1-e^{-r\left(t_{f}+\lambda\right)}\right)
$$

so that the administrative delay prolongs the profit period, but does not affect the trade-off that determines the optimal entry time. Therefore, the entry time for a domestic leader is the same as that of a foreign leader: $\mathrm{t}_{L A}^{\lambda}=\frac{1}{r}$.

We can now assess the impact of an administrative delay on the preemption dates of the two firms. Equating the profits for a domestic leader to those of a domestic follower, and substituting in the optimal waiting times of the followers, results in the following expression:

$$
\begin{gathered}
e^{-r t_{l}} \int_{0}^{t_{f B}^{\lambda}} \theta N t_{l} e^{-r x} d x=e^{-r\left(t_{l}+t_{f A}^{\lambda}\right)} \int_{0}^{\infty} \theta N t_{f A}^{\lambda} e^{-r x} d x \Longleftrightarrow \\
t_{l}\left(1-e^{-1} e^{-r \lambda}\right)=\frac{e^{-1}}{r}
\end{gathered}
$$

where the $t_{l}$ on the right hand side of the first expression stands for the application date of the foreign leader. The preemption date of the domestic firm is $t_{P A}^{\lambda}=\frac{1}{r} \frac{e^{-1}}{1-e^{-1} e^{-r \lambda}}$. This is earlier than the preemption date in the baseline case. Intuitively, for a given date of first entry $t_{l}$, the administrative delay does not affect the domestic firm's discounted profits as a follower but it increases the profits of the domestic firm as a leader by delaying the introduction of the second-generation product. Hence, at the preemption time of the baseline case, the domestic firms has higher profits as a leader 
than as a follower so that it is willing to move even earlier in order to move first.

To obtain the foreign preemption date we equate the profits of the foreign firm, assuming that it leads, with the profits of the foreign firm, assuming that it follows, to obtain:

$$
\begin{aligned}
e^{-r t_{l}} \int_{\lambda}^{t_{f A}^{\lambda}} \theta N t_{l} e^{-r x} d x & =e^{-r\left(t_{l}+t_{f B}^{\lambda}+\lambda\right)} \int_{0}^{\infty} \theta N t_{f B}^{\lambda} e^{-r x} d x \\
& \Longleftrightarrow e^{-r t_{l}} N t_{l}\left(e^{-r \lambda}-e^{-1}\right)=e^{-r\left(t_{1}+\frac{1}{r}+\lambda\right)} \theta N\left(\frac{1}{r}\right)
\end{aligned}
$$

so that the earliest date at which the foreign firm would be willing to preempt is $t_{P B}^{\lambda}=\frac{e^{-1} e^{-r \lambda}}{r\left(e^{-r \lambda}-e^{-1}\right)}$. Note that, at a zero administrative delay, this preemption date is the same as the baseline preemption date. Further, $\frac{\partial t_{L}^{B}}{\partial \lambda}>0^{21}$. Intuitively, the administrative delay hurts the discounted profits of a foreign follower less than those of a foreign leader because the fruitless period between application and actual introduction intervenes at a later date. This makes the foreign firm less eager to move early in order to be first.

Summarizing, an administrative delay $\lambda$ does not affect the stand alone date of a domestic leader, postpones the stand alone date of a foreign leader by exactly $\lambda$, decreases the preemption date of the domestic firm and increases the preemption date of the foreign firm. For small values of $\lambda$, then,

$$
\begin{aligned}
& { }^{21} \partial t_{L}^{B} / \partial \lambda= \\
& -e^{-1}\left[\left\{1-\left(e^{-r \lambda} /\left(e^{-r \lambda}-e^{-1}\right)\right)\right\} e^{-r \lambda} /\left(e^{-r \lambda}-e^{-1}\right)\right] \\
& \text { which is positive for } \lambda<\frac{1}{r} .
\end{aligned}
$$


we have $t_{P A}^{\lambda}<t_{P B}^{\lambda}<t_{l A}^{\lambda}=\frac{1}{r}<t_{l B}^{\lambda}=\frac{1}{r}+\lambda$. In the unique subgame perfect equilibrium, the domestic firm introduces first at $t_{P B}^{\lambda}$. The foreign firm applies for approval at time $t_{P B}^{\lambda}+\frac{1}{r}$ and begins selling its product after a further delay of $\lambda$. This ranking remains valid as long as:

$$
t_{P B}^{\lambda} \leq t_{l A}^{\lambda} \Longleftrightarrow e^{-r \lambda} \geq \frac{e^{-1}}{1-e^{-1}}
$$

For all greater values of $\lambda$, we have $t_{P A}^{\lambda}<t_{l A}^{\lambda}=\frac{1}{r}<t_{P B}^{\lambda}<t_{l B}^{\lambda}=\frac{1}{r}+\lambda$ so that the domestic firm introduces first at time $\frac{1}{r}$.

As we saw in the benchmark case, $\frac{1}{r}$ is the welfare maximizing date of first introduction for the home country. Moreover, home welfare is independent of the date of introduction of the second-generation product. This implies that home welfare is maximized by setting the administrative delay at or above $\lambda^{*}$ such that $e^{-r \lambda^{*}}=\frac{e^{-1}}{1-e^{-1}}$. With the optimal delay, the welfare of Country A is:

$$
W_{A}^{\lambda}=\frac{e^{-1} \theta N}{r^{2}}=W_{A}^{S}<W_{A}^{\mu}
$$

In other words, just like the optimal tariff, the optimal delay ensures the best possible timing of product introduction for country A but it does not yield any tariff revenue. Therefore, as long as tariffs are not bounded, the home country will maximize welfare by using its trade policy and will not discriminate against the foreign firm in its administrative approval process. 
Administrative delays will only be used if trade liberalization decrease the maximum allowable tariff significantly below $\mu=\frac{\theta}{r}$.

We can now compute world welfare under the optimal delay, $W^{\lambda^{*}}$ and compare it to world welfare under the optimal tariff, $W^{\mu^{*}}$ :

$$
\begin{gathered}
W^{\lambda^{*}}=\int_{1 / r}^{\infty} \theta N\left(\frac{1}{r}\right) e^{-r x} d x+\int_{\frac{2}{r}+\lambda}^{\infty} \theta N\left(\frac{1}{r}\right) e^{-r x} d x=\frac{N \theta}{r^{2}} e^{-1}\left(1+e^{-1} e^{-r \lambda^{*}}\right) \\
W^{\mu^{*}}=\frac{N \theta}{r^{2}} e^{-1}\left(1+2 e^{-2}\right)
\end{gathered}
$$

From the definition of the optimal administrative delay, however, we know that:

$$
\mathrm{e}^{-r \lambda^{*}}=\frac{e^{-1}}{1-e^{-1}}<2
$$

Therefore, from the point of view of world welfare, the optimal tariff is preferable to the optimal administrative delay. This result is not a priori obvious since tariff revenues are a pure transfer that has no effect on world welfare, and the date of first introduction is the same under both policies. The only differences between the two policies lie in the timing of introduction of second generation products and in their quality. On the one hand, second generation products are introduced earlier with the optimal delay than with the optimal tariff ${ }^{22}$. On the other hand, with the delay, the quality of the second generation product only keeps increasing over the interval between

${ }^{22}$ Formally, $\frac{2}{r}>\frac{1}{r}+\lambda^{*}$. At the optimal administrative delay, $\mathrm{e}^{-r \lambda}=\frac{e^{-1}}{1-e^{-1}}$ and the right hand side of this equation is strictly greater than $\mathrm{e}^{-1}$. This implies that $\lambda^{*}$ is strictly less than $\frac{1}{r}$. 
the first introduction and the date of application of the foreign firm. This is followed by a period of length $\lambda^{*}$ during which the product goes through the approval process without any further quality improvements. This contrasts with the tariff regime, where the quality of the second-generation product keeps increasing over the whole interval between the two introduction dates. This second effect dominates.

Finally, the foreign firm is better off under the optimal delay, where it earns discounted profits of $\frac{N \theta e^{-2}}{\left(1-e^{-1}\right) r^{2}}$, than under the optimal tariff policy, where its discounted profits would be equal to $\frac{N \theta e^{-2}}{r^{2}}$. In other words, the disadvantage of facing a period, $\lambda^{*}$,of stunted product development is outweighed by the burden of the optimal tariff.

\section{Trade Liberalization}

Under the GATT/WTO, trade liberalization has taken the form of mutually agreed reductions in quotas and/or tariffs. While significant effort has been expended to also restrict the use of other, less obvious, discriminatory policy instruments the results so far appear to be modest. Accordingly we will assume that trade liberalization sets an upper limit on the tariff that can be used by the home country, but that it does not constrain the use of administrative delays. 
The effects of a drastic trade liberalization are quite striking. If tariffs can no longer be used at all, the home country will switch from the optimal tariff policy to the optimal policy of delay. As we have just seen, this switch would result in lower welfare for the home country and the world, even though it would be applauded by the foreign firm. In other words, the prohibition on tariffs would force the home country to rely on an instrument that is less efficient both for itself and for the world economy.

We can illustrate the effect of less extreme degrees of trade liberalization in figure 3. The tariff cap is on the horizontal axis and the combination of tariff and delay that maximizes domestic welfare is on the vertical axis. Let us consider a progressive tightening of the tariff cap. For values of $\mu_{\max }$ in $\left[\mu^{\#}, \frac{\theta}{r}\right]$, the optimal policy of the home country is to set the maximum tariff allowed and not to impose any administrative delay. Such a policy still ensures that the first introduction occurs at the optimal date $\frac{1}{r}$ and that the discounted value of tariff revenues is as large as possible. Interestingly,

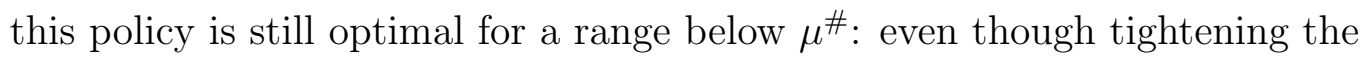
cap now implies that the domestic firm introduces earlier than $\frac{1}{r}$, the home country still prefers not to use administrative delays. Intuitively, for values of $\mu$ close to $\mu^{\#}$, the gains from pushing the introduction date back toward $\frac{1}{r}$ are small ${ }^{23}$. On the other hand, delaying the first introduction involves a

${ }^{23}$ Formally, this follows from the envelope theorem. 
significant decrease in the discounted values of the tariff revenues ${ }^{24}$. As the tariff cap is tightened further, one reaches a point where the marginal benefit of delaying the first introduction outweighs the marginal cost of pushing back the date at which tariff revenues are collected. From that point on, the home country uses both the maximum possible tariff and a positive administrative delay.

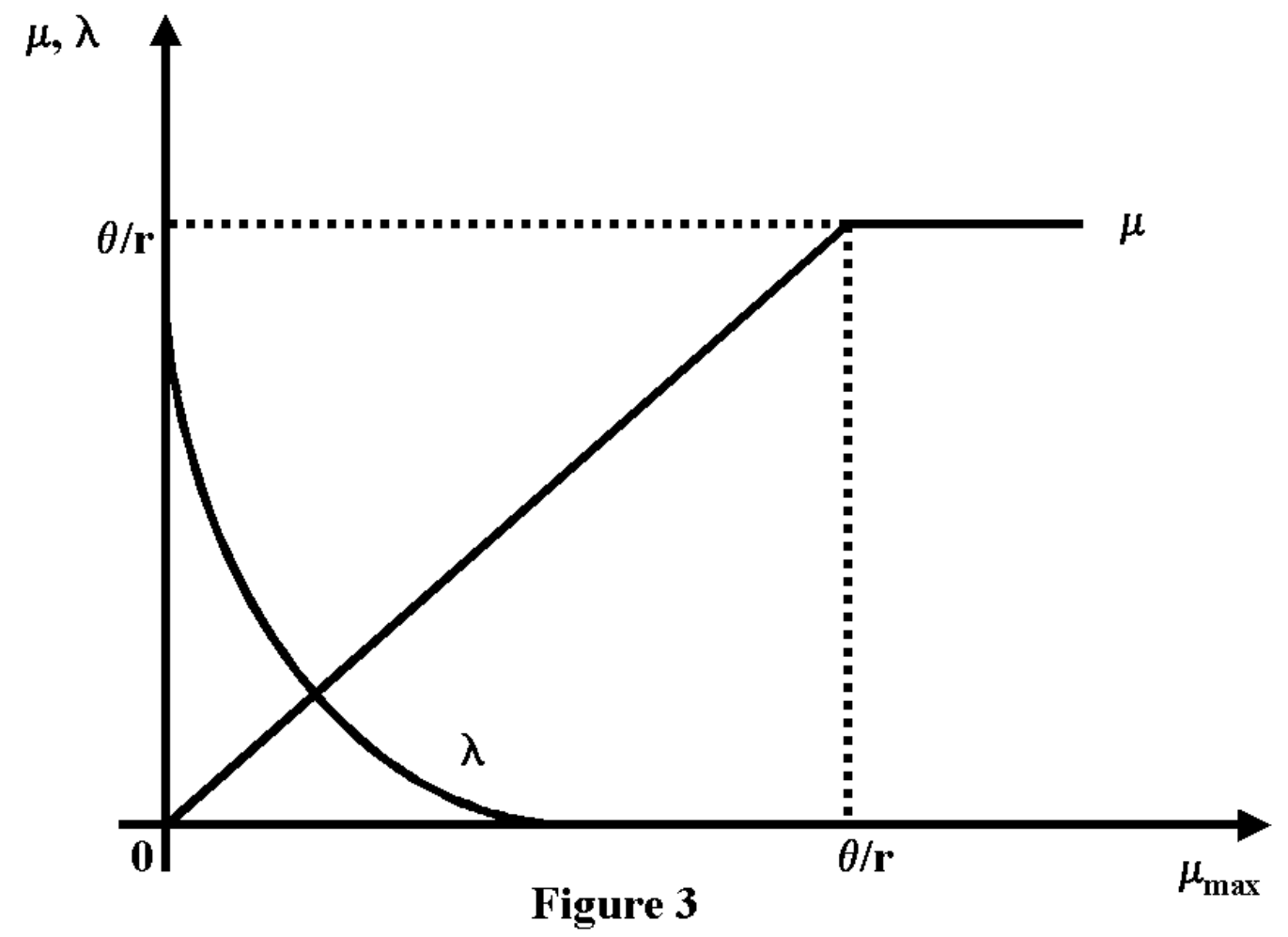

${ }^{24}$ In the absence of tariff cap, there was no such trade off since the value of $\mu$ that maximized the discounted value of tariff revenues was high enough to also ensure first introduction at $\frac{1}{r}$. The difference here is that the tariff rate is fixed at $\mu_{\max }$ so that further delay does not add to tariff revenues. 
As long as the home country does not rely on administrative delays, trade liberalization increases world welfare. Hence, for $\mu_{\max } \in\left[\mu^{\#}, \frac{\theta}{r}\right]$, liberalization decreases the delay between first and second introduction, bringing it closer to the optimal value of $\frac{1}{r}$. Further liberalization has the additional benefit of also speeding up the date of introduction of the first product. However, once the domestic country begins to impose a substantial administrative delay, the dates of introduction of the two products get pushed back, so that further liberalization results in lower levels of world welfare.

Proposition 3 Moderate trade liberalization increases world welfare. Further liberalization gives rise to administrative delays and decreases world welfare.

Proof. See Appendix A section 4.

\section{Robustness}

\subsection{Credibility of the tariff and delay policies}

We have so far adopted the traditional timing of trade policy models by assuming that the level of tariffs and administrative delays could be committed to before the firms made their entry choices. However, the extent to which governments can credibly commit to various types of economic policies is a, yet unresolved, empirical question. It is, therefore, interesting to examine 
how our analysis is affected if we vary the commitment power of the policy maker.

The optimal administrative delay obtained in Section 3 remains optimal at any point of the game and is, therefore, credible in the absence of any exogenous commitment power. After the domestic firm moves first, the policy maker becomes indifferent between all possible values of the delay because, from then on, the instantaneous welfare of the country is equal to $N q_{A}$ whatever the date of introduction and quality of the foreign follower happens to be. If the foreign firm were to move first then the administrative delay would have no effect on the rest of the game so that, again, the policy maker would be indifferent between all possible values of $\lambda$.

The optimal tariff policy derived in Section 3 clearly suffers from one type of time-inconsistency: once the foreign firm has actually introduced its own product, country A would wish to revise its optimal tariff. By setting a unit tariff equal to the quality advantage of the foreign product, country A would appropriate the entire surplus created by the second product introduction, leaving the foreign firm with zero profits. If there is any arbitrarily small but positive cost of entry, such an opportunistic policy on the part of country A would keep the foreign firm out of the industry altogether. Since country A is better off when the foreign firm actually enters, one can at least say that it has an incentive to commit not to revert to this opportunistic tariff policy 
if it possibly can.

On the other hand, $\mu=\theta / r$ remains the optimal value of the tariff as long as the foreign firm has not introduced its product. To see this, suppose that the home government could change the tariff once the home firm has introduced first. At that point, the home government only cares about maximizing the discounted value of its tariff revenues. The value of the superior quality embedded in second generation products is completely appropriated by the foreign firm and does not enter into the domestic welfare function. Hence the government chooses the value of $\mu$ that maximizes:

$$
\int_{t_{f B}^{\mu}}^{\infty} \mu e^{-r x} d x, \text { where } t_{f B}^{\mu}=\frac{1}{r}+\frac{\mu}{\theta}
$$

yielding $\mu^{*}=\frac{\theta}{r}$, which is the same as the optimal tariff that would be chosen at the beginning of the game.

\subsection{Demand}

We have assumed that consumer demand for either product is perfectly inelastic at any point in time. Inelastic demands have the convenient property that a monopolist would behave in a socially optimal way, as it is able to appropriate the whole consumer surplus created by its product. This helps to ensure that any departure from the socially optimal pattern of introduction has its source in the rivalry between the domestic and foreign firms. Still, inelastic demands have some important limitations. 
The first limitation is that import tariffs do not result in the usual deadweight loss. Hence inelastic demands bias the world welfare comparison in favor of the tariff policy. The second peculiarity of inelastic demands is that they allow each quality leader to fully appropriate the value of its quality advantage. This is why the home government in our model was indifferent as to the precise level of quality attained by a foreign follower: local consumers could not appropriate any part of this increased quality. To investigate the effect of this special feature, we reconsider the analysis of Sections 1 through 4 under the assumption that the foreign firm can only appropriate a fraction, $\alpha$, of its quality advantage. Hence the instantaneous profits of a foreign leader would be $\alpha \theta t_{l}$ and the profits of a foreign follower would be $\alpha \theta t_{f}$. When a tariff is imposed, we assume that a proportion, $\alpha$, is borne by the foreign firm and a proportion, $1-\alpha$, by local consumers. ${ }^{25}$

\footnotetext{
${ }^{25}$ This assumption would hold for linear demands, where the proportion between profit and consumer surplus is independent of the tariff level. Alternative assumptions about the sharing of the tariff burden would not significantly affect the nature of the results.
} 


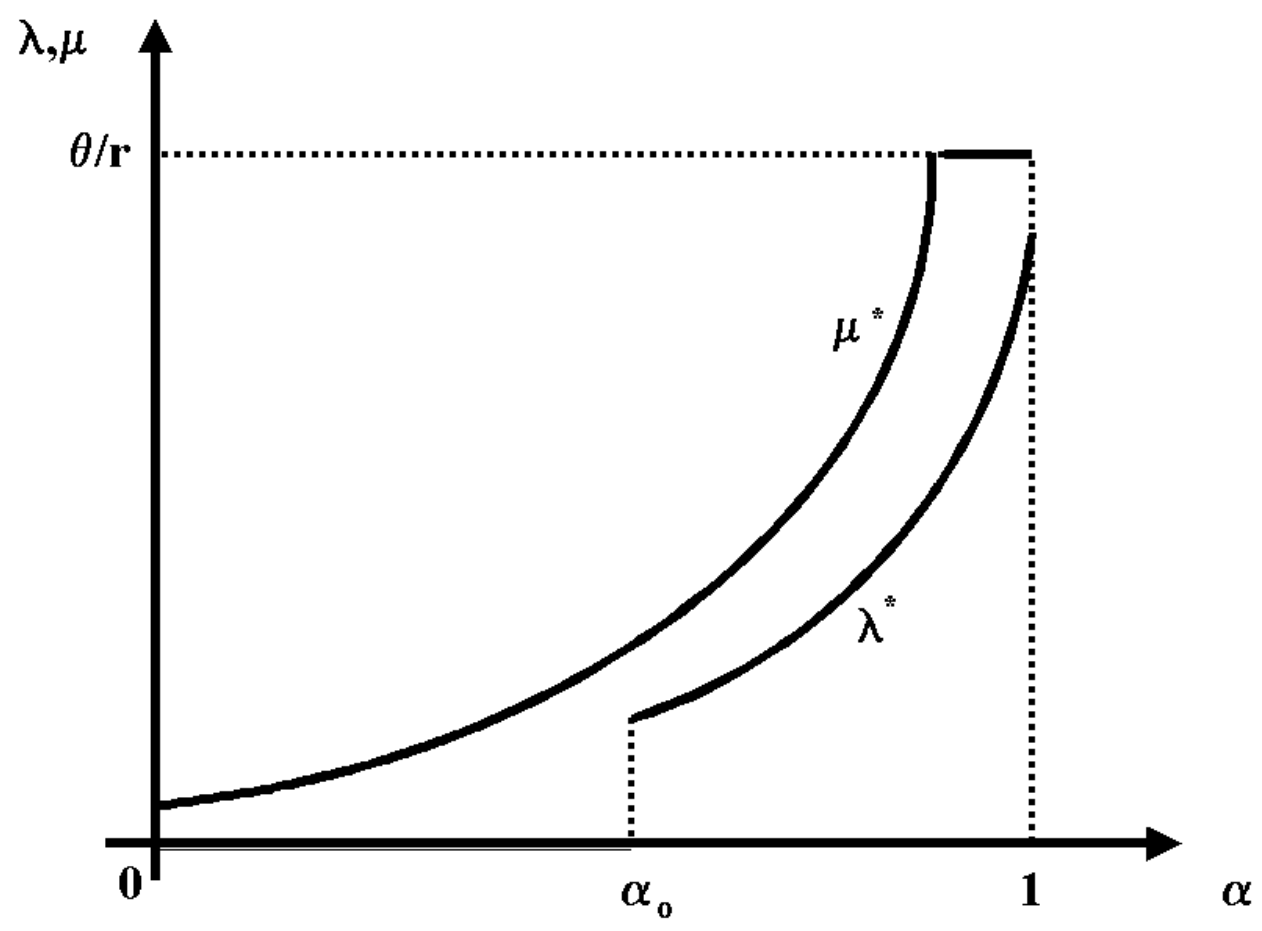

Figure 4

With this specification, $(1-\alpha)$ enters all profit maximization problems as a multiplicative factor, leaving the dates of introduction of leaders and followers as well as preemption dates unchanged. Since these dates are independent of $\alpha$, the effect of tariffs and delays on the behavior of the firms is still as described in the previous sections. On the other hand, the welfare function of country A now includes some of the surplus created by the foreign firm, so that country A now cares about not overly delaying the introduction of the foreign product. This makes the use of both delays and tariffs less attractive, for two reasons. First, for a given date of introduction by the 
domestic leader, administrative delays and tariffs push back the introduction of the foreign good. Second, tariffs and delays also defer the date of introduction of the domestic leader, further postponing the introduction of the second product.

The optimal tariff and delay policies are shown as a function of $\alpha$ in figure 4. As expected, both instruments are used less aggressively when $\alpha$ is low. Interestingly, there is a critical value $\alpha_{o}$ below which the optimal administrative delay is zero. The intuition for this discrete jump can be obtained from figure 5. Country A 's welfare is made of two parts. The first component, $W 1$, is the value of the product of the domestic firm. This value is appropriated by the home firm from the first to the second introduction and by domestic consumers after that. $W 1$ only depends on the delay $\lambda$ through its effect on the date of introduction of the domestic product. As we saw in the previous sections, $W 1$ is maximized by an introduction date of $\frac{1}{r}$, which occurs for $\lambda$ larger than $\lambda_{o}$. Over this range, then, $W 1$ is independent of $\alpha$. Below $\lambda_{o}, W 1$ is increasing in $\lambda$. The second component, defined as $W 2$, represents the share $(1-\alpha)$ of the foreign firm's quality advantage that is captured by country A. Since a larger delay pushes back the date of introduction of the foreign product and also freezes its quality for a longer period, $W 2$ is decreasing in $\lambda$. The sum of $W 1$ and $W 2$ is two-peaked, with a local maximum at $\lambda=0$ and another one at $\lambda^{*}>0$. As the share of the foreign firm 's quality advantage appropriated by the home country increases, 
so does the relative importance of $W 2$ and, therefore, the relative height of the $\lambda=0$ peak. For $\alpha<\alpha_{o}$ then, $W$ is maximized at $\lambda=0 .{ }^{26}$

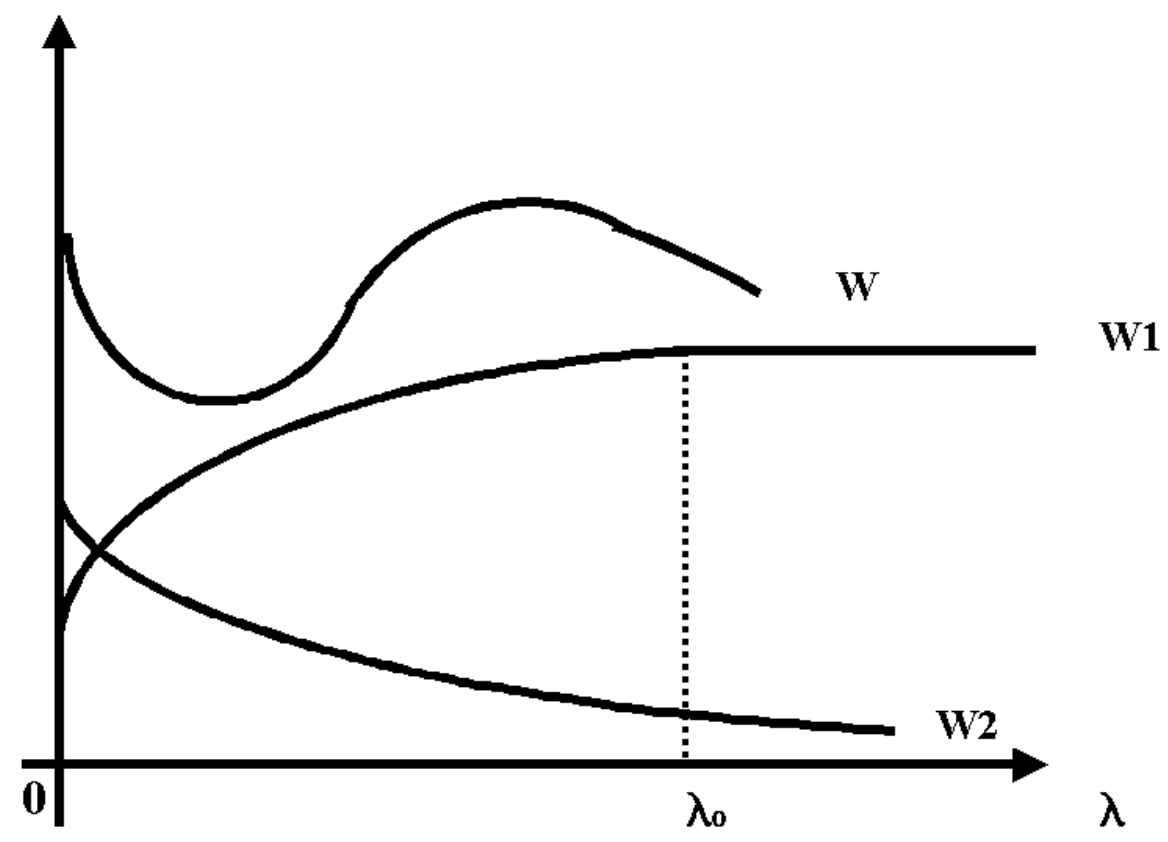

Figure 5

While the introduction of the parameter $\alpha$ does not affect our positive results or the qualitative analysis of the home country's welfare, it can change the implications of trade liberalization for world welfare. Since $\alpha$ only determines how surplus is shared between the foreign firm and country A it does

${ }^{26}$ See Appendix B for a description of the proofs and simulations on which the results of this section rely. 
not have any direct effect on world welfare. Its impact comes through the induced changes in the optimal policies of country A. As long as the optimal delay is positive, our previous conclusion still holds: world welfare is higher under country A's optimal tariff than under its optimal delay. Hence drastic liberalization would lower world welfare. However, as soon as $\alpha$ hits the critical value for which the optimal delay jumps to zero, the policy conclusion is reversed: the optimal delay policy ensures the prevalence of free trade while the optimal tariff results in undesirably late introductions. Therefore, for $\alpha$ low enough, drastic trade liberalization would increase world welfare.

\section{Conclusion}

Despite efforts to reduce formal trade barriers, administrative procedures still stand out as a source of differential treatment of foreign and domestic firms. In this paper we have focussed on the case of product approval, where discrimination imposes additional delays on the introduction of new products by foreign competitors. We have compared the effects of such administrative delays with those of more traditional trade policy instruments such as tariffs. Using a simple model of the timing of product introduction we have shown that both tariffs and delays postpone the date of introduction of both foreign and domestic products and, further, allow the domestic firm to be first to market. It is significant that we can show that administrative delays as an informal trade barrier can achieve such an end, as the use of such a tool 
is feasible within current institutional structure. We also have established that, if both instruments are available, the domestic country prefers to rely solely on the tariff. Although obtained for the special case of inelastic demands, these positive results are rather robust to changes in demand and cost conditions. While this result is similar to other results comparing less to more efficient trade instruments, our presentation is novel in several ways. First, administrative delays have not been studied formally in the literature, so it is significant that we can illustrate how the result on efficiency carries over in this case. Second, we can illustrate the mechanism by which the tariff dominates the administrative delay. Clearly, this differs from the mechanism by which tariffs dominate other instruments. We also have compared welfare under the domestic country's optimal tariff policy to the level of welfare attained under its optimal delay policy. While the foreign country is better off with administrative delays, world welfare is higher under the optimal tariff. This implies that a drastic trade liberalization that bans the use of tariffs but is ineffective in controlling less transparent policies like delays would actually make the world worse off. In fact one can show that, while imposing a binding cap on tariffs initially increases worldwide welfare, there is a level below which further tightening the cap is undesirable. In this way, we analyze both drastic and partial liberalization and their effects on welfare. Our normative results are significantly less robust than the results on the firms' behavior, however. In particular one can show that they are sensitive to the share of the quality advantage of the (late-moving) foreign firm that 
can be appropriated by domestic consumers. This in turn would depend on the precise specification of demand and on the type of competition between domestic and foreign firms. Our conclusion that drastic trade liberalization would decrease world welfare should therefore be taken as a cautionary tale, not as robust guidance for policy. A more general normative insight from the paper is that constraining the use of a subset of trade-related instruments does not necessarily lead to more palatable equilibrium policies ${ }^{27}$.

\section{References}

- Brander, J.A. and Spencer, B., 1983, "International R\&D Rivalry and Industrial Strategy", Review of Economic Studies, 50, 707-722.

- Chuman, E. and Kusumoto, S-I., 1995, "On the Optimal Timing of Technology Adoption by the Home Firm under Tariff Protection or Free Trade", mimeo, University of Tsukuba.

- Dranove, D. and Metzler, D., 1994, "Do Important Drugs Reach the Market Sooner?", Rand journal of Economics, Autumn, 402-423.

- Dutta, P.K. and Rustichini, A., 1993, "A Theory of Stopping Time Games with Applications to Product Innovations and Asset Sales", Economic Theory 3, 743-764.

${ }^{27}$ An interesting extension of our analysis would be to allow both countries to have active trade policies. For this to affect our results, there must of course be some kind of link between the two markets. One natural assumption would be that simultaneous introduction in both markets is more economical than staggered entry. 
- Gieringer, D.H., 1985, "The Safety and Efficacy of New Drug Approval", Cato Journal 5, 177-201.

- Myagiwa, K. and Ohno, Y., 1995, "Closing the Technology gap under Protection", American Economic Review, September, 755-770.

- Noll, R., 1985, "Government Regulatory Behavior: A Multidisciplinary Survey and Synthesis", in R. Noll (ed.), Regulatory Policy and the Social Sciences, Berkeley, University of California Press.

- Prokop, J., Regibeau P., and Rockett, K., 1993, "Minimum Quality Standards and Novelty Requirements in a Onse-Shot Development Race", Working Paper, Northwestern University, Department of Management and Strategy.

- Regibeau, P. and Rockett, K.,1996, "The Timing of Product Introduction and the Credibility of Compatibility Decisions", International Journal of Industrial Organization 14, 801-823.

\section{Appendix A}

\section{Derivation of the optimal tariff in case 2}

The home country's welfare is written as follows:

$$
W_{A}=\int_{1 / r}^{\infty} N \theta\left(\frac{1}{r}\right) e^{-r x} d x+\int_{\frac{2}{r}+\frac{\mu}{\theta}}^{\infty} N \mu e^{-r x} d x
$$


Maximizing this expression with respect to $\mu$ yields $\mu^{*}=\frac{\theta}{r}$.

2. Showing that $\mu^{*}$ is the globally optimal tariff for the home country when only the tariff may be used.

Welfare of Country A is composed of two terms, as written above: a term that represents the sum of profits and consumers' surplus net of the tariff revenue, and a second term reflecting tariff revenue:

$$
W_{A}=\int_{t_{l}}^{\infty} N \theta t_{l} e^{-r x} d x+\int_{t_{l}+t_{f B}^{\mu}}^{\infty} \mu N e^{-r x} d x
$$

It is straightforward to show that the first term is maximized at $t_{l}=\frac{1}{r}$. Therefore, to prove that the optimal tariff occurs for $\mu>\mu^{\#}$ we only need to show that the second term is maximized for $\mu>\mu^{\#}$. We maximize the following expression with respect to the tariff level:

$$
\max \mathrm{e}^{-r t_{L}} e^{-e t_{f}} \frac{N \mu}{r}
$$

subject to:

$$
\begin{aligned}
& \mathrm{t}_{f}=\frac{1}{r}+\frac{\mu}{\theta} \\
& \mathrm{t}_{l}=\frac{e^{-1} e^{-\frac{r \mu}{\theta}}}{r\left(1-e^{-1}\right)}+\frac{\mu}{\theta}
\end{aligned}
$$


The first order conditions of this maximization problem are:

$$
\mathrm{e}^{-r t_{L}} e^{-r t_{f}} \frac{N}{r}\left[1-r \mu\left(t_{L}^{\prime}+t_{f}^{\prime}\right)\right]=0
$$

where the primes indicate first derivatives, which can be calculated as follows:

$$
\begin{aligned}
& \mathrm{t}_{L}^{\prime}=\frac{1}{\theta}\left(1-\frac{e^{-1} e^{-\frac{r \mu}{\theta}}}{1-e^{-1}}\right)>0 \\
& \mathrm{t}_{f}^{\prime}=\frac{1}{\theta}>0
\end{aligned}
$$

In order to have an interior maximum the expression in square bracket in the first order condition must be equal to zero. This expression is positive at $t_{l}=\frac{1}{r}$ and decreases in the tariff level (i.e., its derivative with respect to the tariff is negative for $\mu<\frac{\theta}{r}$ ). This implies that any possible interior solution must occur for $t_{l}>\frac{1}{r}$ or, equivalently, for $\mu>\mu^{\#}$.

This means that the maximum of expected profit over the range $\mu \epsilon$ $\left[0, \mu^{\#}\right]$ must be at a corner. Clearly, expected tariff revenues cannot be maximized for $\mu=0$. They cannot be maximized for $\mu=\mu^{\#}$ either: at this point the expression for discounted tariff revenues is continuous and, by definition of $\mu^{*}=\frac{\theta}{r}$ we know that discounted tariff revenues are higher at $\mu^{*}$ than at $\mu^{\#}$. 


\section{Derivation of the optimal entry dates for both firms when} the home country can control both firms' entry dates

In order to derive the optimal entry dates for both firms from the point of view of Country A, we must maximize welfare with respect to both the entry dates of the leader and the follower. Since consumers' surplus is the same as profits, Country A's welfare is simply the expression at the top of the page with the tariff set to zero. This expression is independent of the entry date of the follower, indicating that the optimal entry date for the follower is indeterminate. Maximizing the expression with respect to the leader's entry date yields an optimal time of entry of $t_{l}=\frac{1}{r}$. Welfare for Country A is the same as in the monopoly case, not surprisingly.

The optimal entry dates from the point of view of world welfare are calculated by maximizing world welfare with respect to the entry dates of the leader and the follower. The welfare of Country A is as specified in the previous paragraph, while the welfare of Country B is simply the discounted profits of the follower, as calculated in the first equation of the Appendix (setting the tariff equal to zero). Maximizing world welfare yields a follower entry delay of $\frac{1}{r}$ (since the optimal date is indeterminate from the point of Country A, and a delay of $\frac{1}{r}$ maximizes the follower's profits, as in the baseline case discussed in the text). The first order condition that determines the leader's entry date is: 


$$
\mathrm{e}^{-r t_{l}} \frac{\theta}{r}\left[1-r t_{l}-e^{-1}\right]=0
$$

so that the optimal entry date for the leader is $\mathrm{t}_{l}=\frac{1-e^{-1}}{r}$. This is earlier than the optimal entry date from the point of view of Country A since world welfare takes into account Country B's welfare, and from the point of view of Country B, the leader's entry date merely serves to postpone the date at which profits will accrue to Country B. At the world welfare maximizing entry dates for the two firms, welfare is as follows:

$$
\mathrm{e}^{1-e^{-1}}\left(1-e^{-1}\right) \frac{\theta N}{r^{2}}=W_{A} \quad \mathrm{e}^{-1} \frac{\theta N}{r^{2}}=W_{B} \quad \frac{e^{-1} \theta N}{r^{2}}\left(1+e^{e^{-1}}\left(e^{2}-e\right)\right)=W
$$

\section{Partial Liberalization.}

We first consider the range $\mu_{\max } \in\left[\mu^{\#}, \frac{\theta}{r}\right]$. The welfare of the home country has two components, $W_{o}=e^{-r t_{l}} N \theta t_{l}$ and the tariff revenue $T=$ $e^{-r t_{l}} e^{-1} e^{-r \frac{\mu}{\theta}} \mu$. The first component is maximized by any $\mu \geq \mu^{\#}$ since $t_{l}=\frac{1}{r}$ for all $\mu \geq \mu^{\#}$. Moreover $T$ is concave in $\mu$ and $\operatorname{argmax} T=\frac{\theta}{r}$. Hence, for $\mu \in\left[0, \mu_{\max }\right] \operatorname{argmax} T=\mu_{\max }$. Hence the optimal policy is to set $\mu=\mu_{\max }$. As the date of first introduction is unchanged but the date of second introduction moves closer to the worldwide optimum, liberalization over this range increases world welfare.

Now we show that, in the neighborhood of $\mu_{\max }=\mu^{\#}$, the optimal policy does not involve a positive administrative delay. In the absence of any delay, 
the optimal tariff policy is still to set $\mu=\mu_{\max }$ as $\frac{d W_{o}}{d \mu}\left(\mu=\mu_{\max }\right)>0$ and $\frac{d T}{d \mu}\left(\mu=\mu_{\max }\right)>0$. At $\mu=\mu_{\max }$ we have $\frac{d W}{d \lambda}=\frac{\partial W_{o}}{\partial t_{l}} \frac{d t_{l}}{d \lambda}+\frac{d T}{d \lambda}$. At $\mu=\mu={ }_{\max }=\mu^{\#}, \frac{\partial W_{o}}{\partial t_{l}}=0$ by the envelope theorem (since for $\mu=\mu^{\#}$, $\left.t_{l}=\frac{1}{r}=\operatorname{argmax} W_{o}\right)$. Since $\frac{d T}{d \lambda}<0$ we have $\frac{d W}{d \lambda}<0$. One can therefore find an arbitrarily small neighborhood to the left of In the neighborhood of $\mu=\mu={ }_{\max }=\mu^{\#}$, for which $\frac{d W}{d \lambda}$ remains negative.

The precise shape of the functions displayed in figure 3 for $\mu_{\max }<\mu^{\#}$ were obtained through numerical simulations based on Maple V.

\section{Appendix B}

We now assume that the foreign firm can only appropriate a share $\alpha$ of its quality advantage. We first show that the introduction of $\alpha$ does not affect the various dates of introduction. Clearly the maximization problem of the domestic firm as a leader or as a follower do not depend on $\alpha$. The maximization problem of a foreign follower becomes

$\operatorname{Max}_{t_{f}} e^{-r t_{f}} \alpha\left[\theta t_{f}-\mu\right]$ so that $t_{f}^{*}=\frac{1}{r}+\frac{\mu}{\theta}$ and $\operatorname{Max}_{t_{f}} e^{-r t_{f}+\lambda} \alpha \theta t_{f}$ so that $\mathrm{t}_{f}^{*}=\frac{1}{r}$ and the delay before actual introduction is $\frac{1}{r}+\lambda$.

Similarly, the maximization problems of a foreign leader are: 
$\operatorname{Max}_{t_{l}} e^{-r t_{l}} \alpha\left(\theta t_{l}-\mu\right)\left(1-e^{-r t_{f A}}\right)$ so that $t_{l}^{*}=\frac{1}{r}+\frac{\mu}{\theta}$ and $\operatorname{Max}_{t_{l}} e^{-r t_{l}+\lambda} \alpha \theta t_{l}$ so that $t_{l}^{*}=\frac{1}{r}$ and the delay before actual introduction is $\frac{1}{r}+\lambda$.

The preemption dates of the domestic firms clearly do not depend on $\alpha$. For the foreign firms, the preemption dates are obtained as follows. With a tariff,

$$
e^{-r t_{p}} e^{-1} e^{-r \frac{\mu}{\theta}} \alpha\left[\frac{\theta}{r}+\mu-\mu\right]=e^{-r t_{p}} \alpha\left(\theta t_{p}-\mu\right)\left[1-e^{-1}\right] \text { so that } t_{p B}=\frac{1}{r} \frac{e^{-1}}{1-e^{-1}} e^{-\frac{r \mu}{\theta}}+
$$

$\frac{\mu}{\theta}$. With a delay, $e^{-r t_{p}} e^{-1} e^{-r \lambda} \alpha \frac{\theta}{r}=e^{-r t_{p}} \alpha \theta t_{p}\left(e^{-r \lambda}-e^{-1}\right)$ so that $t_{p B}=$ $\frac{e^{-1} e^{-r \lambda}}{r\left(e^{-r \lambda}-e^{-1}\right)}$.

Results on optimal policies could not be obtained analytically for all ranges of parameters. We, therefore, relied on numerical simulations based on Maple V. The simulations are quite straightforward as the only parameters of the problem are $\theta$ and $r$. In fact, the only magnitude of relevance is the relative size of these two parameters so that one can set $\theta=1$ and determine the optimal delay and tariff policies for different values of $r$. As the qualitative results are the same for all values of $r$, figures 4 and 5 in the text simply show a 'typical' outcome. The expressions used in the simulations are:

$$
\begin{aligned}
& W(\mu)=\frac{e^{-r t_{l}}}{r}\left[\theta t_{l}+\alpha \mu e^{-1} e^{-r \frac{\mu}{\theta}}+(1-\alpha)\left(\frac{1}{r}+\mu\right) \theta e^{-1} e^{-r \frac{\mu}{\theta}}\right] \\
& W(\lambda)=\frac{e^{-r t_{l}}}{r}\left[\theta t_{l}+(1-\alpha) \frac{\theta}{r} e^{-1} e^{-r \lambda}\right] \\
& W W(\mu)=\frac{e^{-r t_{l}}}{r}\left[\theta t_{l}+\theta\left(\frac{1}{r}+\mu\right) e^{-1} e^{-r \frac{\mu}{\theta}}\right]
\end{aligned}
$$


$\left.W W(\lambda)=\frac{e^{-r t_{l}}}{r}\left[\theta t_{l}+\frac{\theta}{r} e^{-1} e^{-r \lambda}\right)\right]$

where $t_{l}=\min \left[t_{p B}, \frac{1}{r}\right]$. 